\title{
Results of Interbank Exchange Rates Forecasting using State Space Model
}

\author{
Muhammad Kashif \\ Sub-campus, University of Agriculture Faisalabad \\ at Depalpur, Pakistan \\ kashif_uaf@yahoo.com \\ Islam-ud-Din Shehzad \\ Department of Mathematics and Statistics \\ University of Agriculture Faisalabad, Pakistan \\ S.M. Bokhari \\ State Bank of Pakistan, Karachi, Pakistan \\ Niyyar Munir \\ Department of Mathematics and Statistics \\ University of Agriculture Faisalabad, Pakistan
}

\begin{abstract}
This study evaluates the performance of three alternative models for forecasting daily interbank exchange rate of U.S. dollar measured in Pak rupees. The simple ARIMA models and complex models such as GARCH-type models and a state space model are discussed and compared. Four different measures are used to evaluate the forecasting accuracy. The main result is the state space model provides the best performance among all the models.
\end{abstract}

Keywords: Exchange Rate, State Space Modeling, Pakistan.

\section{Introduction}

From a policy point of view, the behavior of exchange rate fluctuation is very important. To invest money in any country, the investor wanted to know about the exchange rate change over time. Make a wrong guess about the exchange rate movement; one could lose a substantial amount of money. Thus the awareness about volatility modeling and forecasting of foreign exchange rate is very important for policy makers and investors. The volatility of financial time series, its modeling and forecasting has attracting growing attention in finance and trading. Large literature and research on forecasting volatility shows its impact on trade. For the prediction of volatility many econometric models has been reviewed by many scientists, however, no single model is preferred to capture volatility dynamics. In different stock market and forecasting volatility studies many researcher (Akgiray 1989, Pagan and Schwert 1990 and Brooks 1989 while studying US stock data) preferred GARCH model and some favoured (Tse 1991 and Tse and Tung 1992 while studying Japanese and Singaporean stock market data) the weighted moving average model. The Yu (2002) find that the stochastic volatility model provides the best performance for forecasting volatility in the New Zealand stock market while comparing nine alternative models. On the other hand, however, little work has been reported (Timmer and 
Andreas 1997) for modeling volatility using state space models and specifically to Pakistan's financial market.

The linear state space model has become a standard modeling framework for the statistical analysis of time series. This includes estimation, signal extraction, forecasting, and seasonal adjustment of time series in economics, engineering, statistics, and empirical finance. The use of state space become popular in the statistical community only after it was introduced for stochastic system identification by autoregressive moving average (ARMA) modeling (Akaik, 1974) and in the dynamic linear model (Harrision and Stevens, 1976). By the 1980 the state space model was a popular tool for handling non-stationary time series (Harvey, 1989; Kitagawa and Gersh, 1984). The role of state space in modeling macroeconomic time series and analyzing business cycles is discussed by Harvey (1989), Hamilton (1994), and Kim and Nelson (1999). Other discussions of state space approaches to time series analysis is found by Brockwell and Davis (1987), Shumway and Stoffer (2000). The purpose of this study is to compare the performance of state space model with ARMA and GARCH model for forecasting the interbank exchange rates of US $\$$ measured in Pakistan rupees. This paper is organized as fellows. In section 2 , the data set is described and the three competing models are reviewed. At the end the measure used to assess the performance of the model are presented. The section 3 and 4 describes the empirical findings and conclusions.

\section{Methodology}

\subsection{Data}

To achieve the goal of the study, the data of daily closing inter-bank exchange rate of Pak. rupee vs. US dollar, measured as rupee price of dollar are taken. The data is taken from The State Bank of Pakistan (S.B.P) with sample period from July 1, 2001 to June30, 2007. There are total of 1769 daily observations because the official markets remain close on Sunday.

\subsection{Competing Model}

The most scientific way to model the series is to construct an appropriate model based on statistical considerations. The constructed model should be very simple and capable for good and accurate forecasting. Therefore model building is an important part of time series analysis (Chatfield; 2004). Here we describe and summarize the three models used for forecasting. At the first stage we discuss the simple ARMA models then two complex models. For the estimation purpose the EVIEW and SAS (statistical software) have been used.

\section{ARMA Model}

If the values of the series $\left\{Y_{T}\right\}$ at time $t$ depends only on its previous (linear) values and on a random noise. Mathematically

$$
\mathrm{Y}_{\mathrm{t}}={ }^{\prime} \mathrm{t}-1^{+}{ }^{\prime} 2 \mathrm{t}-2^{+\cdots \cdots+{ }^{\prime}} \mathrm{p} \mathrm{t}-\mathrm{p}{ }^{+} \mathrm{t}
$$


Where $\varphi=\left(\varphi_{1}, \varphi_{2}, \ldots ., \varphi_{\mathrm{p}}\right)$ are model parameters. This model is known as autoregressive (AR) model. The process $\left\{Y_{T}\right\}$ is said to be a moving average process of order $\mathrm{q}$ if $Y_{T}$ can be written as

$$
\mathrm{Y}_{\mathrm{t}}={ }_{\mathrm{t}}+{ }_{1 \mathrm{t}-1}+2 \mathrm{t}-2^{+\cdots \cdots+} \mathrm{q} \mathrm{t}-\mathrm{q}
$$

where $\theta=\left(\theta_{1}, \theta_{2}, \ldots . ., \theta_{q}\right)$ are the moving average (MA) coefficients. By combining the AR (p) and MA (q) parts, we get a mixed autoregressive moving average $(A R M A)$ process of order $(p, q)$. Mathematically

$$
\mathrm{Y}_{\mathrm{t}}-^{\prime} 1 \mathrm{t}-1{ }^{-}{ }^{\prime} 2 \mathrm{t}-2^{-\cdots \cdots-{ }^{\prime}} \mathrm{p} \mathrm{t}-\mathrm{p}=\mathrm{t}^{+} 1 \mathrm{t}-1^{+} 2 \mathrm{t}-2^{+\cdots \cdots+} \mathrm{q} \mathrm{t}
$$

By introducing the back shift operator L, i.e., $L^{i} Y_{t}=Y_{t-i}$ then the $\operatorname{ARMA}(p, q)$ model can be written as

$$
\varphi(\mathrm{L}) \mathrm{Y}_{\mathrm{t}}=\theta(\mathrm{L}) \varepsilon_{\mathrm{t}}
$$

where $\varphi(\mathrm{L})=1-\varphi_{1} \mathrm{~L}-\varphi_{2} \mathrm{~L}^{2}-\cdots \cdots \varphi_{\mathrm{p}} \mathrm{L}^{\mathrm{p}}$ and $\theta(\mathrm{L})=1-\theta_{1} \mathrm{~L}-\theta_{2} \mathrm{~L}^{2}-\cdots \cdots \theta_{\mathrm{q}} \mathrm{L}^{\mathrm{q}}$

In practice, most time series are non-stationary. If the observed time series is non-stationary, we can difference the series. The ARMA model can be written as

$$
(1-\mathrm{L})^{\mathrm{d}} \mathrm{t}^{\prime}=\mathrm{t}
$$

which is called the autoregressive integrated moving average (ARIMA) model and is expressed as $\operatorname{ARIMA}(p, d, q)$. Clearly, the ARIMA process constitutes of three parts, an autoregressive part $(A R)$, a differencing part (I), and a moving average part (MA).

The Box -Jenkins methodology (1994) is used to identify the appropriate model which best describes the series. Autocorrelation function (ACF) and partial autocorrelation function (PACF) will be used for identification. The identified model will be estimated via ordinary least square (OLS) method. The estimated model will be tested by battery of diagnostic tests. Finally the best fitted model will be then go under various residual and normality test and only qualifying model will be selected and reserved for forecasting purpose.

\section{GARCH Models}

The GARCH model is proposed by Bollerslev (1986) and defined by

$$
\left\{\begin{array}{l}
R_{t}=u+\sigma_{t} \varepsilon_{t} \\
\sigma_{t}^{2}=\alpha+\sum_{j=1}^{q} \lambda_{j}\left(R_{t-j}-u\right)^{2}+\sum_{j=1}^{p} r_{j} \sigma_{t-j}^{2}
\end{array}\right.
$$

Define $s_{t}=R_{t}-u, \mathrm{~m}=\max (\mathrm{p}, \mathrm{q}), \lambda_{\mathrm{i}}=0$ for $\mathrm{i}>\mathrm{q}$ and $\mathrm{r}_{\mathrm{i}}=0$ for $\mathrm{i}>\mathrm{p}$. The selection of $p$ and $q$ is an important empirical question. The simple $\operatorname{GARCH}(1,1)$ model is 
used as a candidate model in this study because in most study this model had been found to be adequate (Yu, 2002).

The representation of $\mathrm{GARCH}(1,1)$ variance is

$$
\sigma_{t}^{2}=\alpha+\lambda \varepsilon_{t-1}^{2}+\gamma \sigma_{t-1}^{2}
$$

The $\sigma_{t}^{2}$ is the one-period ahead forecast variance based on past information and is called the conditional variance. The three specified function in this equation are constant term $\alpha$, the news about volatility from the previous period as the lag of the squared residual from the mean equation, $\varepsilon_{t-1}^{2}$ and Last period's forecast variance, $\sigma_{t-1}^{2}$.

\section{STATE SPACE Models}

The state space model is a system consisting of two processes: The unobserved latent process, $\left\{\alpha_{t}\right\}$, and the observation process $\{\mathrm{Yt}\}$. A linear state space representation is given by the system of equations as

$$
\begin{aligned}
& \alpha_{t}=T_{t} \alpha_{t-1}+\varepsilon_{t}, \text { state equation, } \\
& \text { where } \\
& \varepsilon_{t} \sim N_{p}\left(0, H_{t}\right) \\
& \begin{array}{c}
Z_{t}{ }_{t}+{ }_{t}, \\
\text { where }
\end{array} \\
& \eta_{t} \sim N_{p}\left(0, Q_{t}\right)
\end{aligned}
$$

In the definition we have introduced the following notation:

$\alpha_{t}$ : The m-dimensional latent state vector of the system at time $\mathrm{t}$.

$\mathrm{T}_{\mathrm{t}}$ : $\quad$ The $\mathrm{m} \times \mathrm{m}$ transition matrix at time $\mathrm{t}$. It is the design matrix for the latent process, and usually consists of known functions of covariates and possible previous observations.

$\varepsilon_{1}$ : The $\mathrm{N}$-dimensional error vector at time $\mathrm{t}$. $\mathrm{H}_{\mathrm{t}}$, which is allowed to be singular. The $H_{t} s$ are assumed independent, i.e. $\left\{H_{t}\right\}$ is a white noise sequence.

$y_{t}: \quad$ The N-dimensional observation vector at time t.

$Z_{t}$ : The $\mathrm{N} \times \mathrm{m}$ design matrix. It links the state vector to the observation vector.

$\eta_{t}$ : The g-dimensional observation error at time $t$.

$\mathrm{Q}_{\mathrm{t}}$ : which is assumed to be non-singular. The $\eta_{t} \mathrm{~s}$ are assumed independent, i.e. $\left\{\eta_{t}\right\}$ is a white noise sequence.

The most important assumption is that the disturbances $\left\{\varepsilon_{t}\right\}$ and $\left\{\eta_{t}\right\}$ are uncorrelated with each other in all time periods and uncorrelated with initial state. Given estimate of $T_{t}, Z_{t}, H_{t}$, and $Q_{t}$ forecasts of $Y_{t}$ are computed from the conditional expectation of $Z_{t}$. 


\section{Evaluation Measures}

The root mean square error (RMSE), mean absolute error (MAE), mean absolute percent error (MAPE) and Theil inequality co-efficient (TIC) are used to measure the forecast accuracy. They are defined by

$$
\begin{aligned}
& \text { RMSE }=\sqrt{\frac{1}{T} \sum_{i=1}^{T}\left(\begin{array}{cc}
\lambda_{i}^{2} & 2 \\
i & i
\end{array}\right)^{2}} \\
& \text { MAE }=\frac{1}{T} \sum_{i=1}^{T}\left|\begin{array}{ll}
\wedge_{i}^{2} & 2 \\
i
\end{array}\right| \\
& \text { MAPE }=\left[\frac{1}{T} \sum_{i=1}^{T}\left|\begin{array}{ll}
\lambda_{i}^{2} & 2 \\
i
\end{array}\right|\right] \times \\
& \text { TIC }=\frac{\sum_{i=1}^{T}\left(\hat{\sigma}_{i}^{2}-\sigma_{i}^{2}\right)^{2}}{\sum_{i=1}^{T}\left(\hat{\sigma}_{i-1}^{2}-\sigma_{i}^{2}\right)^{2}}
\end{aligned}
$$

The first two measures are the most popular measures and commonly used for testing the forecasting power of a model. These simple measures are symmetric and are not invariant to scale transformation. On the other hand the Theil inequality coefficient is symmetric and invariant to scale transformation. To evaluate the accuracy of various forecasting methods many authors have advocated and recommended these measures.

\section{Results and Discussions}

The time plot of the original series for the period July 1, 2001 to June30, 2007 is shown in Fig. 1. The series shows the downward trend and there observed some stability after the year 2005 .

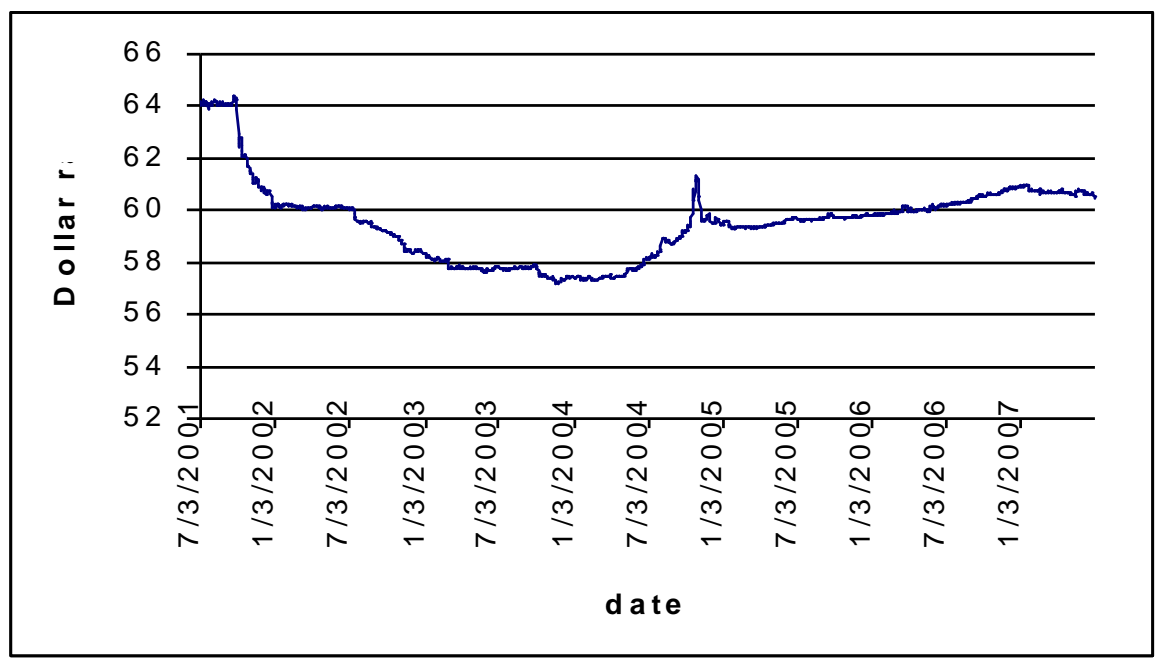

Figure 1: General Trend of US \$ Exchange Rate in Pak Rupees (2001-2007) 
Table 1 show the some summary statistics of the original, first difference series of the entire sample. The table shows sample maximum is 64.3968 which happened in September 2001 and minimum 57.1976 which happened in November, 2003. The mean of first difference is fairly small. The first difference and second difference series shows higher peaks and fatter tails than the normal distribution. The results are in accordance with the findings of Westerfield (1977), Rogalski and Vinso (1978), Kocenda (1995) and Asif (2002). The Skewness coefficient indicates that first difference series is substantially skewed; a common feature of most of the time series. Finally the kurtosis coefficient, which is the measure of the thickness of tail of the distribution are very high, implying that the assumption of Guassianity is dubious. Moreover, the Jarque-Bera test for normality of the distribution yield values which are much greater than the critical value at any conventional level, thus rejecting the null hypothesis of normal distribution. These finding confirm the presence of stylized facts in exchange rate data.

Table 1: Summary statistics of the original and first difference series and test for non-stationarity

\begin{tabular}{|l|c|c|}
\hline \multicolumn{1}{|c|}{$\begin{array}{c}\text { Summary } \\
\text { Statistics }\end{array}$} & $\begin{array}{c}\text { Original } \\
\text { Series }\end{array}$ & $\begin{array}{c}\text { First Difference } \\
\text { Series }\end{array}$ \\
\hline No. of Observations & 1769 & 1768 \\
\hline Mean & 59.5735 & -0.0021 \\
\hline Median & 59.6929 & 0.0016 \\
\hline Skewness & 0.8350 & -3.7894 \\
\hline Kurtosis & 4.5089 & 73.5721 \\
\hline Maximum Value & 64.3968 & 0.4643 \\
\hline Minimum Value & 57.1976 & -0.9159 \\
\hline Jarque-Bera Statistics & $373.3532^{*}$ & $371122.1^{*}$ \\
\hline ADF test for unit root & $-1.7305^{\mathrm{ns}}$ & $-29.9286^{*}$ \\
\hline
\end{tabular}

In table 1 the results of the unit root test for original and first difference series are also presented. The ADF statistics are -1.730 and -29.928 respectively. The original series shows the presence of unit root and is infact non-stationary. The exact conclusion is drawn after the visual inspection of the time plot of the same series. On the other hand the ADF test for the first difference series is highly significant. The graphical representation in figure 2 and significant ADF test of the first difference series proved it to be stationary. 


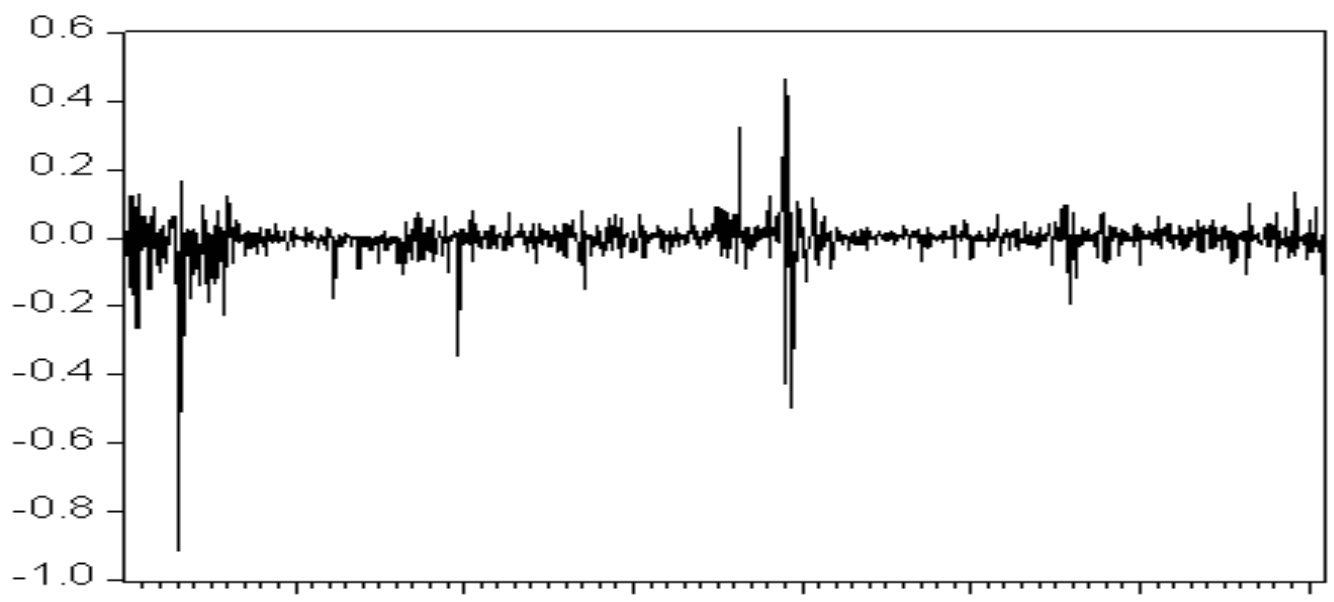

Figure 2: First difference series of US \$ Exchange Rate in Pak Rupees (2001-2007)

From this graph, two particularly volatile periods can be easily identified. The sample kurtosis is 73.57 for the first difference series. This suggested that the unconditional distribution of volatility is not normal.

The careful look at ACF and PACF plots of the first difference series suggests different ARMA models. Highly subjective exercise has been done and different $A R, M A$ terms keeping in view the properties of residuals like independence, homoskedasticity and normality is estimated. Finally with the help of ACF and PACF plots and other information criterion like Akaike and Schwarz statistics, $R^{2}$, adjusted $R^{2}$ and log-likelihood value, the best fitted model is autoregressive with significant lags at 1 and 4. i.e. $\operatorname{ARMA}[(1,4), 0]$.

Similarly we fit a simple $\operatorname{GARCH}(1,1)$ model, to the first difference series of daily closing inter-bank exchange rate of Pak. rupee vs. US dollar, measured as rupee price of dollar using backcast values for the initial variance and Bollerslev Wooldridge standard error in Eview.

For the forecasting from state space model, it is necessary to replace the unknown elements of the system matrices by their estimates. At the first step we determined the state vector. The choice of state vector is based on canonical correlation analysis as proposed by Akaike (1976). After identifying the state vector the state space model is estimated by approximate maximum likelihood. After the parameters are estimated forecasts are produced from the fitted state space model using kalman filtering technique.

\section{Forecast Evaluation}

The one-step ahead forecast from $\operatorname{AR}(2), \operatorname{GARCH}(1,1)$ and state space model is calculated. The main results of four measures of accuracy under the estimated model are presented in table 3 . From the examination of table 3 it is noted that the RMSE statistics indicates that state space models provides the most accurate forecast than the $\operatorname{GARCH}(1,1)$ and $\mathrm{AR}(2)$ models. The MAE statistics 
favors the $\mathrm{GARCH}(1,1)$ model little bit but MAPE statistics also supports the better performance of state space model. Under the Theil inequality coefficient the best model is again state space model followed by $A R(2)$ model.

Table 3: $\quad$ Forecast Evaluation Results of Competing Models

\begin{tabular}{|l|c|c|c|c|}
\cline { 2 - 5 } \multicolumn{1}{c|}{} & RMSE & MAE & MAPE & TIC \\
\hline AR(2) & 0.0533 & 0.0254 & 177.11 & 0.9591 \\
\hline GARCH(1,1) & 0.0534 & 0.0253 & 123.01 & 0.9851 \\
\hline SSM & 0.0499 & 0.0255 & 88.18 & 0.3542 \\
\hline
\end{tabular}

\section{Conclusion}

This research paper focuses on the modeling and prediction of daily inter bank exchange rate of US dollar measured in Pakistan rupees. Three classes of methods, ARIMA scheme, GARCH and state space approach have been described and compared for forecasting the interbank exchange rates. One of the important model considered here is the state space model. Despite its intuitive appeal, the state space model has received no attention in Pakistan. After comparing the forecasting performance of all three models, it was found that the state space model is superior according to the RMSE and TIC. In this sense we say state space model have better structure than ARIMA and GARCH models. Also state space model are morkovian in nature and calculation needed to implement such models are recursive. Further these models can handle large data sets without a disproportionate increase in the computational burden as compared to other competing models.

\section{Acknowledgements}

The author would like to thank the State Bank of Pakistan for providing the data set.

\section{References}

1. Akaike, H. 1974. Markovian representation of stochastic processes and its application to the analysis of autoregressive moving average processes, Annals of the Institute of Statistical Mathematics, 26, 363-387.

2. Akgiray, V. 1989. Conditional heteroscedasticity in time series of stock returns: Evidence and forecast, Journal of Business. 62, 55-80.

3. Asif, M. 2003.Modeling volatility in interbank exchange rate of Pak Rs / US \$ using GARCH: Theory and Application, with comparative study of forecasting performance. Deptt. Of Mathematics and Statistics, Uni. of Agriculture, Faisalabad.

4. Bollerslev, T. 1986. Generalized autoregressive conditional heteroskedasticity. Journal of Econometrics 31, 307-327. 
5. Box, G. E. P., G.W. Jenkins, and G.C. Reinsel. 1994. Time Series Analysis: Forecasting and Control (3rd edn). Englewood Cliffs, New Jersey: Prentice-Hall.

6. Brockwell, P. J. and R.A. Davis. 1987. Time Series: Theory and Models. New York: Springer- Verlag.

7. Brooks, C. 1998. Predicting stock index volatility: Can market volume help? Journal of Forecasting, 17, 59-80.

8. Chatfield, C. 1996. The Analysis of Time Series: An introduction. CRC.Boca.FL. $5^{\text {th }}$ edition.

9. Hamilton, J. D. 1994. Time Series Analysis, Princeton University Press, Princeton.

10. Harrison P.J. and C.F. Stevens. 1976. Bayesian Forecasting. J. Roy.Statist. Soc. Ser. B, 34:1-41.

11. Harvey, A. C. 1989. Forecasting, Structural Time Series Models and the Kalman Filter, Cam-bridge University Press, Cambridge.

12. Kim, C. J. and Nelson, C. R. 1999. State Space Models with Regime Switching, MIT Press, Cambridge, Massachusetts.

13. Kitagawa, $\mathrm{G}$ and Gersch, W. 1984. A smoothness priors-stat space modeling of time series with trend and seasonality. J. American Statist. Asso. 79: 378-389.

14. Kocenda, E. 1995. Volatility of a Seeming Fixed Exchange Rate. Working Paper, University of Housten, U.S.A.

15. Pagan, A. and Schwert G.W. 1990. Alternative models for conditional stock volatilities, Journals of Econometrics, 45: 267-90.

16. Rogalski, R. J. and J. D. Vinso. 1978. Empirical properties of foreign exchange rates. Journal of International Business Studies. Vol. 9: 69-79.

17. Shumway, R. H. \& Stoffer, D. S. 2000. Time Series Analysis and Its Applications, Springer- Verlag, New York.

18. Timmer, J and Andreas S.W. 1997. Modeling Volatility Using State Space models. Inter. J. of Neural Systems, Vol. 8, 4:385-398.

19. Tse, Y.K. 1991. Stock return volatility in the Tokyo stock market, Japan and the Word Economy, 3,285-98.

20. Tse, Y.K. and Tung, S.H. 1992. Forecasting Volatility in the Singapore stock market, Asia Pacific Journal of Management, 9: 1-13.

21. Westerfield, J.M. 1977. An examination of foreign exchange risk under fixed and floating rate regimes. Journal of International Economics. Vol. $35,1-2: 23-45$.

22. Yu, J. 2002. Forecasting Volatility in the New Zealand Stock Market. Applied Financial Economics, Vol. 12: 193-202. 